\title{
NEOLITHIC TO HISTORIC IN THE HONG KONG REGION
}

\author{
William Meacham \\ Centre of Asian Studies, Pokfulam Road, University of Hong Kong, Hong Kong
}

\begin{abstract}
This paper examines relationship between the prehistoric period of Neolithic/Bronze Age and the historic period represented by the Han, Six Dynasties and Tang dynasties. Neolithic and Bronze Age sites are described and the issue of a possible hiatus between late prehistoric and early historic periods is discussed, using available C14 dates.
\end{abstract}

\section{INTRODUCTION}

The history of Hong Kong as a port and British colony (now returned to China as a "special administrative region") is generally well recorded. When it was ceded to Britain in 1841 , the island was described, in the famous (and now highly ironic) phrase, as "a rock with hardly a house upon it." The neighboring islands supported a few scattered fishing villages, while Kowloon peninsula and the New Territories to the north were settled by rice farmers of several large clans.

It was not until the early 20th century that scholars began to examine the pre-British period of Hong Kong's history. Reliable documentary evidence extends back to the early years of the Ch'ing dynasty (late 17th century). Genealogies of the major New Territories clans indicate initial settlements in the Ming, Yuan and possibly Sung periods (10th to 16th centuries). A few tantalizing earlier documentary references exist which may correlate with places in Hong Kong; salt industries and pearl fisheries may have been practised here in the first millennium AD.

Archaeological investigation began in the 1920s and showed that Hong Kong had a much longer history of human occupation, extending back to the Neolithic. Sites abound on outlying islands and along the coastline of the New Territories. More than one hundred sites of the Neo- lithic and Bronze Age have been recorded, and many have been systematically surveyed or excavated. The results of this research have been well published in recent decades, and scientific studies of excavated materials have thrown much light on prehistoric life in the area. A large brick chamber tomb of the Han period (220 BC-AD 206), discovered in 1955 during construction of a public housing estate, marks the beginning of the historical era. Work in the 1970's shed considerable light on the occupation of the territory during the first millennium AD with the discovery of dozens of lime kiln sites belonging to the Six Dynasties and Tang eras.

It is the relationship between the prehistoric period of Neolithic/Bronze Age and the historic period represented by the Han, Six Dynasties and Tang eras that I wish to examine later in this paper. First, I will describe in general terms the cultural evolution and chronology that has been established thus far. Much of this work has been done in the last fifteen years, which has seen a veritable explosion of archaeological work in Hong Kong. This increased tempo of fieldwork has been powered mainly by the rapid pace of urban development and the pressure it has generated on favourable land and archaeological sites. Fortunately, the same period has seen an informal "desire" on the part of government to observe a formal policy that archaeological sites will not be destroyed willy-nilly without proper investigation.

\section{THE NEOLITHIC PERIOD}

The period from 10,000 to $5,000 \mathrm{BC}$ is still very poorly understood in Guangdong. Most of the evidence relating to this "Early Neolithic" era has come from cave sites in the interior. There is only one site in Hong Kong that is securely dated to the very end of this period. It is on top of a small hill on Kau Sai Chau, in the eastern New Territories. There are two $\mathrm{C} 14$ dates from the site, both giving results (calibrated) of around 5200-4900 BC. Only stone 
tools and flakes were found at the site; there was no pottery. Another site, Tung Wan on Lantau, has an "aceramic" phase with chipped stone tools at the base of a Middle Neolithic layer, but there are no $\mathrm{C} 14$ dates and no stratigraphic break to distinguish it. Some doubt thus remains whether it is really a separate cultural phase or simply an idiosyncrasy of that particular site. In the light of the evidence from Kau Sai Chau, it seems likely that Tung Wan also represents this earliest known period of Hong Kong's prehistory. It is not yet proven that these earliest inhabitants did not have or know of pottery, but that is the direction the evidence seems to point. I have argued previously that pottery probably had deep chronological roots (at least 6-7000 BC) along the South China coast, but this new evidence seems to suggest otherwise.

The first phase of the Middle Neolithic dates from c. $4400-3600 \mathrm{BC}$ and is marked by fine paste painted pottery, although its occurrence is rare (the main pottery types being plain fine ware and coarse corded ware). The later phase of the Middle Neolithic is dated c.3300-2800 $\mathrm{BC}$ and characterized by fine paste incised pottery, along with the still predominant coarse corded ware. The sites where these two phases are found clearly indicate a coastal population, sheltering in the bays and lagoons of small islands with good anchorage, but probably also venturing into open sea on fishing expeditions. Most of the Middle Neolithic sites are in sand bank or dune deposits 4 to 6 meters above sea level - well above the storm and tidal zones.

At Sham Wan on Lamma Island (Meacham 1978), fish bones (both head grunt Pomadasys hasta and marine catfish Arius leiotetocephalus) and remains of large stingrays and sharks were uncovered in the cultural layer, along with bones of deer and pig. Cremation and inhumation burial were both practised, along with occasional postmortem perforation of the lower jawbone. Placement of whole pots and stone tools in small pits may indicate that secondary burial was also practised. Several burial grounds have been identified from this period, including two on Chek Lap Kok island (Meacham 1994), levelled for the construction of Hong Kong's new airport (which opened on July 6, 1998). These two sites, Fu Dei Wan and Kwo Lo Wan upper, produced quite a number of complete vessels of fine paste incised ware.

The Late Neolithic in Hong Kong and South China generally is marked by a grey ware made of fine clay and stamped with net, trellis, spiral, lozenge and other geometric designs. This "geometric pottery" replaced the fine painted and incised ware of the earlier phases and probably evolved directly from it, as is suggested by parallels in type of clay, method of manufacture and some elements of style. Two phases of the Late Neolithic have also been distinguished: one with well-fired brittle pottery dated at 2600-2300 BC, the other with much greater variety and sophistication in the geometric patterns but paradoxically less well-fired ware, dating to 2100-1600 BC. Many of the sites which had been occupied during the Middle Neolithic continued to be used. One of the preferred types of site was the "tombolo" island formed by a sandbar linking two small land masses. Sites are also found at the mouths of small bays or lagoons. These sites are all well sheltered, but were quite possibly selected in some cases for agricultural use. However, it is quite probable that the sea continued to be the major source of food. Large quantities of fish bone were found in this phase at Sham Wan.

\section{THE BRONZE AGE}

The rise of Bronze Age cultures during the second millennium BC in South China has traditionally been seen in the light of the impact of Shang and Chou civilizations on the more primitive southern "barbarians". In recent years, however, evidence has been brought to light of equally early bronze-working cultures in northern Vietnam, northeast Thailand, Sichuan province and the Lower Yangtze Basin. From Late Neolithic to Bronze Age in the Hong Kong area, life appears to have continued in much the same way as in earlier times. Most of the same sites were occupied, with beaches on small sheltered bays and sand bars on the islands continuing to be the preferred type of site. But the importance of the tombolo island as a shelter or activity area seems to have declined.

Fishing remained a major subsistence activity. At Sham Wan, several thousand bones of head grunt were virtually the only type of fish found, for reasons unknown. Bronze fish-hooks and pebble net weights were also discovered there. Shellfish were another major source of food, and shell remains indicate that sandy, muddy and rocky shores were all being exploited for shell food resources.

The local Bronze Age is characterized of course by bronze artifacts, but at most sites these are few and fragmentary. Fish-hooks, projectile points, knives and axe heads are the most commonly found types; moulds for the manufacture of vessels, bells and hairpins have also been found. There are a few traditionalist archaeologists who have maintained doubts that Guangdong and southeast China had a "true" Bronze Age as distinct from the early Iron Age beginning c.500 BC. The excavation in 1989-91 of Sha Po Tsuen on Lamma provided conclusive data on the dating. A clearly defined cultural layer was identified, with several moulds for casting bronze axes in intimate association with high-fired geometric pottery. Also found 
were traces of bronze slag and several samples of charcoal and charred fish bone which were dated to c.1400-900 $\mathrm{BC}$. The site is the first bronze-casting site to be discovered in Guangdong. Pairs of bivalve bronze moulds were found in burials at Kwo Lo Wan on Chek Lap Kok, with $\mathrm{C} 14$ dates in a range of around 1600-800 BC.

A major change did take place, however, in the manufacture of the fine paste pottery. The design of kilns had improved to the stage that very high temperatures could be reached, and much of the geometric pottery was fired at $1200-1300^{\circ} \mathrm{C}$ and is thus extremely hard. A variety of circle, spiral, "double-F", diamond and other geometric patterns decorated the pottery. No local kiln site has been found for this ware and it is assumed that only a few highly specialized kilns produced this stoneware for a large area.

The Bronze Age people in Hong Kong also produced several elaborate rock carvings at locations along the coast, most of them remote and inaccessible. Some of the patterns are abstract and possibly zoomorphic; others are very similar to the geometric decoration on the pottery and date the rock carvings securely to the Bronze Age. The carvings probably had a ceremonial or religious significance related to sea-faring and marine exploitation.

\section{THE HISTORICAL "YUEH" AND CANTONESE}

The southeastern coastal inhabitants were known to the Chinese as the Yueh barbarians. The name was extended southward as the Chinese empire expanded. These Yueh people were noted for their skills in navigation and their savagery in battle; the population of the early state of Yueh (5th-4th centuries BC), centered in the Lower Yangtze, practised wet rice cultivation and engaged in trade along the coast. Modern ethnographic and linguistic researches point to an Austroasiatic or Tai linguistic affiliation for these peoples. The Vietnamese retain the name "Yueh" and the Cantonese are also called "Yuet" (written with a different character but pronounced the same as the earlier character); certainly both groups derive in considerable measure from the aboriginal population.

The Yueh, in Han texts referred to as the "Hundred Yueh", were certainly a diverse population, and may have included peoples of different language families and markedly different customs. The Tai-speaking Chuang of Guangsi province today have oral traditions of earlier occupation of coastal areas and may have been included in the Yueh of Guangdong. Similarly, the Kadai-speaking Li tribes of Hainan Island are almost certainly descended from the Yueh.

A process of gradual though erratic cultural assimilation of the Yueh began after the Ch'in-early Han con- quest, and by the end of Han had brought a large number of the aboriginal Yueh into the sphere of Chinese culture. Han historical texts provide ample evidence of the acceptance of Yueh chiefs and high ranking individuals into the Han administrative system and the military, a fact which may be attested to by the Han tomb at Lei Cheng Uk (discussed further below).

By the Chin-Six Dynasties era (AD 265-589), evidence of renewed and intensive occupation of the beach sites is seen in the lime kilns. This local industry of burning shells and coral to make lime continued until roughly the end of the Tang dynasty (10th century AD) and then died out quite abruptly, perhaps because of overexploitation of the resources (fuel and coral). The people operating these kilns were in my view almost certainly partly assimilated Yueh - the ancestors of the Cantonese. During the Sung and Ming periods (10th-17th centuries), genealogies record that the territory was settled by rice farmers whose descendants form the great clans of the New Territories today.

\section{CHRONOLOGICAL SUMMARY BASED ON C14}

The dating below of each major phase (except for the dynastic periods) is derived from $\mathrm{C} 14$ dates on charcoal; the number of samples is given in square brackets. There are also 29 dates on shell, most of which support the chronology given below.

Paleolithic - no known occupation

Early Neolithic - 5200-4900 BC [2]

Middle Neolithic - 4400-2800 BC

painted pottery phase $4400-3600 \mathrm{BC}$ [9]

incised pottery phase $3300-2800 \mathrm{BC}$ [12]

Late Neolithic - 2600-1600 BC

Yung Long phase 2600-2300 BC [15]

classic soft geometric phase 2100-1600 BC [8]

Bronze Age - 1600-800 BC [16]

Early Historical periods -

Han dynasty 220 BC-AD 206 [0]

Chin-Tang dynasties AD 265-907 [25]

\section{CONTINUITY / HIATUS}

The C14-based chronology above illustrates clearly there is a major gap between prehistoric and historical periods. Admittedly, there are also gaps between each phase, but these are small except for that between Bronze Age and Han, leaving aside the newly discovered Early Neolithic. This major gap from $800 \mathrm{BC}$ to about $200 \mathrm{BC}$ does not seem to be a distortion caused by too few or skewed C14 dates. A total of 21 samples from Bronze Age contexts (16 charcoal and 5 shell) have been dated, as shown in Table 1. Four samples are obviously intrusive; of the re- 
MEACHAM: NEOLITHIC TO HISTORIC IN HONG KONG

Table 1. C14 dates from Bronze Age contexts in Hong Kong

\begin{tabular}{|c|c|c|c|c|}
\hline Site & Sample & $\begin{array}{l}\text { Laboratory Result } \\
\text { (BP 1950) }\end{array}$ & Laboratory Code & $\begin{array}{l}\text { Calibration Result } \\
\text { (BC unless noted) }\end{array}$ \\
\hline Hai Dei Wan, Lantau & $\begin{array}{l}\text { charcoal } \\
\text { charcoal }\end{array}$ & $\begin{array}{l}3360 \pm 80 \\
3200 \pm 160\end{array}$ & $\begin{array}{l}\text { Har-3589 } \\
\text { ANU-2223 }\end{array}$ & $\begin{array}{l}1874-1446 \\
1875-1025\end{array}$ \\
\hline $\begin{array}{l}\text { Kwo Lo Wan } \\
\text { Chek Lap Kok }\end{array}$ & $\begin{array}{l}\text { charcoal } \\
\text { charcoal } \\
\text { charcoal }\end{array}$ & $\begin{array}{l}3020 \pm 70 \\
3220 \pm 80 \\
2840 \pm 60\end{array}$ & $\begin{array}{l}\text { Beta-46868 } \\
\text { Beta-60794 } \\
\text { Beta-45149 }\end{array}$ & $\begin{array}{l}1412-1040 \\
1679-1309 \\
1191-835\end{array}$ \\
\hline $\begin{array}{l}\text { Lung Kwu Sheung Tan } \\
\text { Tuen Mun }\end{array}$ & $\begin{array}{l}\text { charcoal } \\
\text { charcoal }\end{array}$ & $\begin{array}{r}340 \pm 80 \\
2680 \pm 90\end{array}$ & $\begin{array}{l}\text { Beta-40992 } \\
\text { Beta-40993 }\end{array}$ & $\begin{array}{l}1405-1795 \mathrm{AD}^{*} \\
1040-529\end{array}$ \\
\hline Sha Po Tsuen, Lamma & $\begin{array}{l}\text { charcoal } \\
\text { charcoal } \\
\text { charred fish bone } \\
\text { charred fish bone } \\
\text { charred fish bone }\end{array}$ & $\begin{array}{l}2835 \pm 65 \\
2420 \pm 60 \\
3060 \pm 120 \\
2820 \pm 360 \\
2940 \pm 50\end{array}$ & $\begin{array}{l}\text { Beta-31475 } \\
\text { Beta-78217 } \\
\text { OxA-5849 } \\
\text { OxA-5850 } \\
\text { Beta-81206 }\end{array}$ & $\begin{array}{c}1193-829 \\
764-393 ? \\
1591-932 \\
1302-948\end{array}$ \\
\hline Sham Wan, Lamma & charcoal & $866 \pm 194$ & $\mathrm{R}-4585 / 4$ & $860-1400 \mathrm{AD}^{*}$ \\
\hline Tai Wan, Lamma & charcoal & $3670 \pm 80$ & Beta- 42860 & 2281-1781? \\
\hline Tai Long Wan, Lantau & $\begin{array}{l}\text { carbonaceous } \\
\text { pottery }\end{array}$ & $2810 \pm 90$ & Har-5470 & $1251-806$ \\
\hline Tung Wan Tsai, Ma Wan & charcoal & 0 & WK-???? & Modern* \\
\hline Sham Wan, Lamma & shell & $2485 \pm 85$ & $\mathrm{I}-9554$ & $368 \mathrm{BC}-24 \mathrm{AD} ?$ \\
\hline Tai Long, Lantau & shell & $400 \pm 80$ & Har-3588 & $1350-1655 \mathrm{AD}^{*}$ \\
\hline $\begin{array}{l}\text { Tung Wan Tsai } \\
\text { Ma Wan }\end{array}$ & $\begin{array}{l}\text { shell } \\
\text { shell } \\
\text { shell }\end{array}$ & $\begin{array}{l}3210 \pm 40 \\
3580 \pm 70 \\
3630 \pm 60\end{array}$ & $\begin{array}{l}\text { WK-3482 } \\
\text { WK-3486 } \\
\text { WK-3487 }\end{array}$ & $\begin{array}{l}1164-927 \\
1677-1365 \\
1701-1424 \\
\end{array}$ \\
\hline
\end{tabular}

Notes:

$*$ = obviously intrusive

$?=$ problem result

Calibration according to the Calib 3.0.3c program of the Quaternary Isotope Lab, University of Washington, 1994.

Laboratories:

ANU = Australian National University, Canberra; Beta = Beta Analytic Inc. (US); Har = Harwell (UK); I = Teledyne (US);

OxA = Oxford (UK); R = Institute of Nuclear Sciences (NZ); WK = Waikato (NZ).

maining 17 dates, 14 cluster around c.1600-800 BC as seen in Figure 1; one is earlier and two are later. These three outliers might be explained by the old wood effect, residual Neolithic charcoal and contamination. The two samples with late dates of c.780-380 BC and 368 BC-AD 24 are particularly suspect, since the context is precisely the same as the other 14 and is characterized by pottery of a very specialized style (double-f, inter-locking spirals, lozenges and other elaborate geometric designs).

Two interpretations are possible: either the two late dates are due to contamination, or they represent the lingering of this Bronze Age culture on a few sites, perhaps with some minor stylistic evolution not yet isolated from the main phase. The former interpretation seems much more likely.

Regardless of which interpretation one chooses, it 


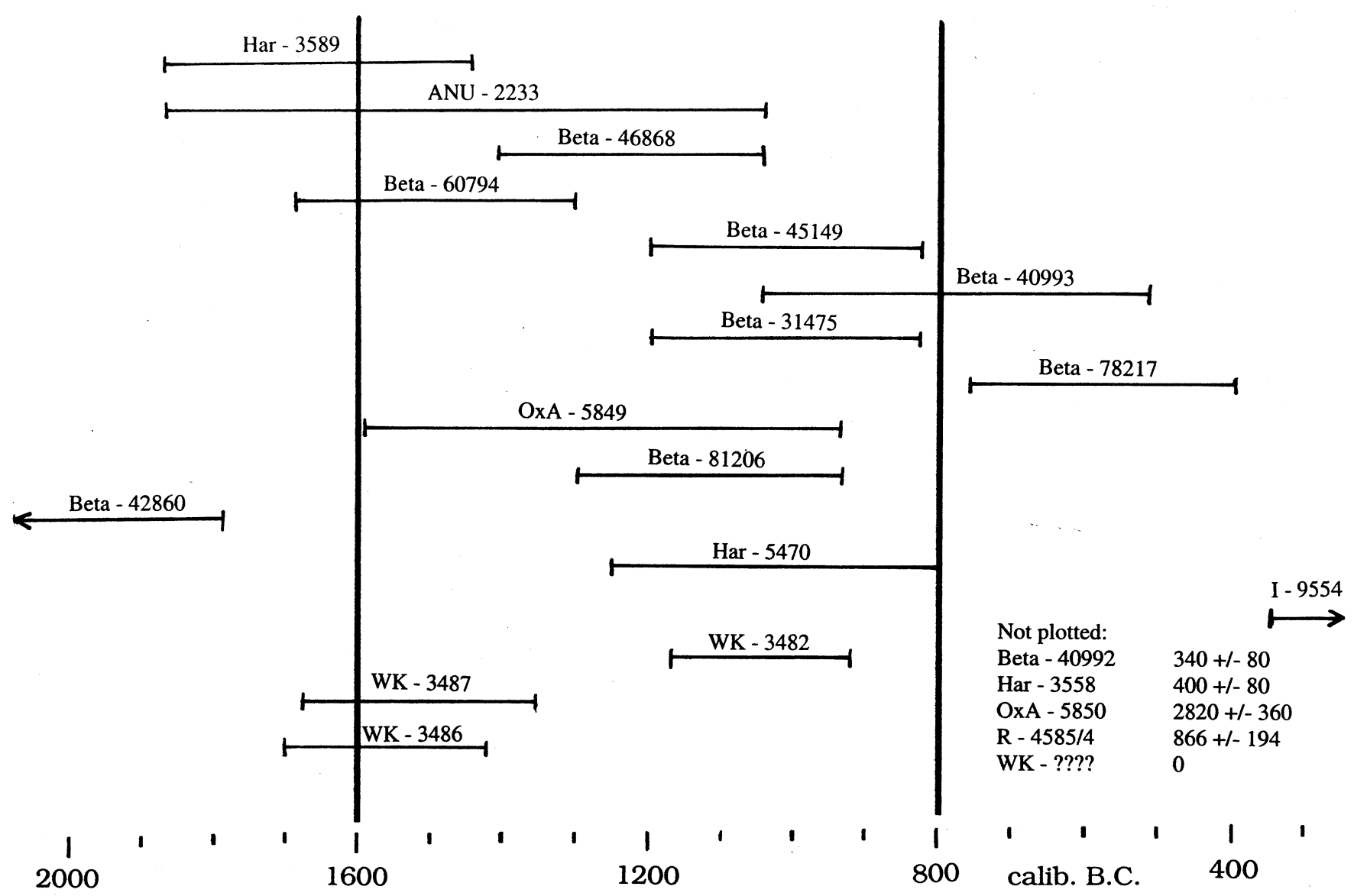

Figure 2. Plot of calibrated C14 dates from Bronze Age contexts in Hong Kong

would appear that there was a significant change after almost 4000 years of near-continuous and thriving occupation of the territory, marked by strong continuities from one phase to the next. From about 800-700 BC, there was a rather sudden hiatus and near-abandonment of the area. This hiatus, which seems so clear from the $\mathrm{C} 14$ chronology, is also revealed by the virtual absence of so-called "Union Jack" or "rice character pattern" pottery in the Hong Kong region. This Early Iron Age pottery (also called "asterisk pattern") is dated by Guangdong archaeologists to roughly 5th-2nd centuries BC (Xu 1984:67) Only a few isolated sherds of asterisk ware have been found in Hong Kong, usually associated with Han pottery.

For the interior of central Guangdong, there is no such decline in archaeological sites, and the Early Iron Age there is quite vigorous, with more than 120 sites with asterisk pottery. Up the coast from Hong Kong, however, Maglioni (1975) found in Haifeng district a pattern of sites similar to Hong Kong's during his surveying in the 1930s: dozens of Neolithic and Bronze Age sites, no asterisk pottery sites, one Han site. Just north of Hong Kong, the Shenzhen region also bears witness to a similar situation, although it does have one site with a substantial Early Iron Age cultural deposit intermingled with Bronze Age material. It also has several modest Han sites and Han burials.

The implication is clearly that the large population suggested by the number and richness of Bronze Age sites in this coastal region had dispersed. The reasons for such a virtual abandonment of what had previously been prime real estate supporting a thriving population through millennia can hardly be guessed at: ecological change creating adverse conditions (perhaps malaria), shifting tribal confederation boundaries creating a "no man's land," or simply erratic and random changes in demographics. None of these speculations seems very appealing and there is at present no satisfactory explanation for the significant depopulation that is indicated by the evidence.

Furthermore, the habitation of the Hong Kong region does not suddenly re-appear in force during the Han era. Twenty years ago, I wrote that the Han was a major miss- 
ing link in Hong Kong archaeology, for despite the large chamber tomb at Lei Cheng Uk there were simply no sites with other than a few sherds of Han pottery. This situation has now changed somewhat and there are a few minor Han sites, one dating to Western Han (first two centuries BC) and a few others dating to Eastern Han (first two centuries AD). Whilst these sites have provided evidence of sparse human presence during the period concerned, they have hardly filled the void. When compared with the wealth and sheer numbers of Bronze Age sites in Hong Kong they are relatively few and meagre:

one minor Western Han site (100-500 sherds): Pak Mong on Lantau;

some very minor Eastern Han sites (less than 100 sherds): Penny's Bay on Lantau, Sha Po Tsuen on Lamma, Leung Kwu Sheung Tan near Tuen Mun;

two minor Eastern Han sites: Kau Sau Chau off Sai Kung, probably of one homestead lasting a few decades; Tung Wan Tsai on Ma Wan, with a thin shell midden layer.

Concerning the last site, Rogers (1995:470) wrote:

At Tung Wan Tsai we have what appears to be a transition from prehistory to history, a record of combined continuity and gradual evolutionary change.

This is not correct sensu stricto; the published report clearly shows that there are two main cultural components to the site. One is Bronze Age and dated by three C14 dates to between 1700 and $900 \mathrm{BC}$, while the second is Han, dated by coins, ceramics and two $\mathrm{C} 14$ dates which fall within the 2 nd century $B C$ to 1 st century AD. There is no occupation between these two phases.

The question that I raised 20 years ago still poses itself today, in a slightly modified form: where is the population and the support base for the wealthy or highly ranked individual who was buried in the Lei Cheng Uk tomb? With all the intensive archaeological work of recent decades, there is still a glaring anomaly between the few minor sites on the one hand, and the administrative/military rank or degree of wealth implied by the tomb on the other. It is quite possible that the evidence for the immediate community or outpost where this individual resided was lost to urban development. But it is scarcely imaginable that the network of settlements and the population normally needed to support or justify such a rich/powerful individual has been missed by archaeology. And it is nonsensical to claim that the contents of the tomb give an idea of what "the daily life of ordinary people" (Watt 1970:9) in Han times in this region was like. The grave goods are stylized artifacts probably imported from Canton (Panyu).

The issue of who was buried at Lei Cheng Uk has been debated from time to time, with discussion centering on whether he was a Han administrative official or garrison commander, or even possibly a local chieftain already assimilated into Han culture (typified by the ruler of the Western Han "Kingdom of Nan Yueh"). The real issue seems to be: what exactly was such a person doing in a region so thinly populated? If it was a garrison placed there for strategic reasons (e.g. to protect the sea approach to Panyu), it must have been one of the loneliest of postings and one which was alimented largely by supply ship. This general sort of question can ultimately be answered, if at all, only by new documentary evidence, but it does pose interesting problems for the archaeologist to ponder.

The population re-appears rather suddenly in abundance during the 4 th and 5 th centuries $A D$ with the rise of the lime industry. Almost all the former beach sites of Neolithic or Bronze Age become, mirabile dictu, scenes of activity and life once again. These folk were probably simple boat people who took up to lime-making as a more attractive economic activity than fishing and marine foraging, or possibly as a seasonal sideline to their usual mode of subsistence. The mystery here is not so much where these people came from as where they lived. No village or house remains have been found, and strangely, very few burials. There is more evidence about the "settlements" of the prehistoric inhabitants, which were probably seasonal or very temporary encampments on natural plateaux 10-20 m above sea level, on low hillslopes behind the sand banks, or on headlands jutting out into the sea. The 1st millennium AD lime kiln workers may have lived, just as perhaps the vast majority of prehistoric inhabitants had done, in simple thatched huts on stilts over tidal mud flat or marsh. What evidence that might have survived of these settlements may eventually be recovered, with regular testing of likely low-lying sites.

It might be argued that a stilt village scenario could also be used to explain how a large Han population might have escaped the notice of archaeology, except for one inconvenient consideration. Boat people living on tidal mudflats and exploiting the sea in this archipelago for their main livelihood could hardly not have used the sand banks and low dunes behind almost every beach in Hong Kong. The evidence of their activities should be there, just as it is in ample proportions for their precursors and successors. The tendency of the terrain to focus people onto those landforms is very strong indeed, and witnessed by dozens of Neolithic/Bronze Age and 1st millennium AD sand bank sites in the small territory of Hong Kong alone. It is also well attested by ethnographic studies of the 19th and 20th century which show how important the back beach areas were to the boat people. It requires too great a leap of fantasy to conjure up any alternatives to the obvious but extraordinary conclusion that presents itself - this area was 


\section{INDO-PACIFIC PREHISTORY ASSOCIATION BULLETIN 18, 1999 (MELAKA PAPERS, VOLUME 2)}

only very sparsely inhabited from about $800 \mathrm{BC}$ to $\mathrm{AD}$ 300.

\section{REFERENCES}

Maglioni, Rafael 1975. Archaeological Discovery in Eastern Kwangtung. Hong Kong: Hong Kong Archaeological Society, Journal Monograph II.

Meacham, William 1976. Sham Wan, Lamma Island; An Archaeological Site Study. Hong Kong: Hong Kong Archaeological Society, Journal Monograph III.

--- 1994. Archaeological Investigations at Chek Lap Kok Island. Hong Kong: Hong Kong Archaeological Society, Journal Monograph IV.
Rogers, Pamela R. 1995. Subsistence continuity in the prehistory of south coastal China. In Yeung Chun-tong and Brenda Li Wai-ling (eds), Archaeology in Southeast Asia, pp. 467-78. Hong Kong: University Museum and Art Gallery, University of Hong Kong.

Watt, James C.Y. [Qu Chi-ren] 1970. A Han Tomb at Lei Cheng $U k$. Hong Kong; Urban Council.

Xu, Hengbin 1984. A general discussion on the Bronze Age of Guangdong. In Peter Y.K. Lam (ed.), Archaeological Finds from Pre-Qin Sites in Guangdong. Hong Kong; Guangdong Provincial Museum and Chinese University of Hong Kong. 


\section{TAHVAYTIISVIO}

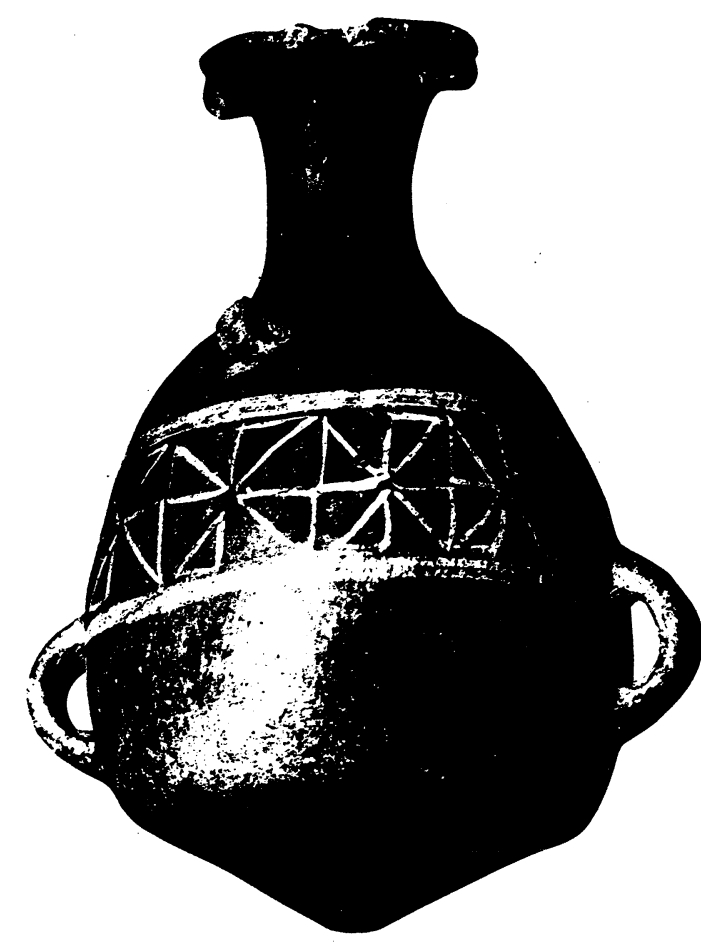

Aribalo procedente del valle central de Cochabamba, Bolivia, Museo Arqueológico de la Universidad Mayor de San Simón, Cochabamba.

\section{TAWANTINSUYU}

Una Revista Internacional de Estudios Inkas An International Journal of Inka Studies

\section{TAWANTINSUYU: AN INTERNATIONAL JOURNAL OF INKA STUDIES}

is edited and produced at the Australian National University.

It is the first comprehensive journal to cover this important late prehistoric Andean civilisation. It is published once per annum at an annual cost of US\$25.00, including postage and packing.

To order your copy and back volumes, send cheque with name and address to

Tawantinsuyu Editorial, LPO Box 177, Australian National University, CANBERRA, ACT 2604, AUSTRALIA 